\title{
Decomposition of Common Curlymesquite Herbage on Edwards Plateau Rangeland,
} Texas

\author{
JAMES F. GEORGE AND FRED E. SMEINS
}

\begin{abstract}
Decomposition of common curlymesquite herbage from a continuously, heavily grazed pasture and one pasture of a 4-pasture deferred rotation grazing system was investigated on the Edwards Plateau of Texas. Decomposition of herbage in litterbags was similar for both pastures. Approximately $40 \%$ of the original herbage weight was lost during the 345-day study. Average decomposition rate was $2.19 \mathrm{mg} / \mathrm{g} /$ day. Rate of decomposition during a 238-day period was significantly related to antecedent potential evaporation and precipitation since the preceding collection date and cumulative time. Percentage nitrogen and percentage ash content increased while percentage carbon and carbon/nitrogen ratio decreased over time in the decomposing herbage.
\end{abstract}

Decomposition of plant materials is an essential process in the cycling of nutrients in natural ecosystems. Decomposition rates influence release of nutrients to the active pool as well as the accumulation of litter and nutrients in the litter layer. This study was conducted to investigate the decomposition of common curlymesquite (Hilaria belangeri (Steud.) Nash), a dominant herbaceous species on Edwards Plateau rangeland in Texas. Specific objectives were: (1) to compare decomposition rates of common curlymesquite herbage from two pastures under different longterm grazing management; (2) to determine the relationship between decomposition and environmental factors; and (3) to determine chemical characteristics of the decomposing herbage.

\section{Study Area and Methods}

Field data were collected on the Texas Agricultural Research Station, Texas A\&M University, near Sonora, Texas. The Station is located within the southwestern portion of the $9,700,000$-ha Edwards Plateau ( $30^{\circ} 15 \mathrm{~N}, 101^{\circ} 30^{\prime} \mathrm{W}$ ) (Gould 1975). The Station consists of 1,402 ha at a mean elevation of $735 \mathrm{~m}$. The growing season averages 240 days and precipitation averages $557 \mathrm{~mm}$ with peaks in spring and fall. Vegetation is a short and midgrass grassland with spraying densities of woody plants (Quercus spp. and Juniperus spp.) that occur singly or in clumps. Soils are clayeyskeletal, montmorillonitic, thermic, Lithic Haplustolls (Soil Conserv. Serv. 1968). The Station is divided into pastures used for the study of grazing management systems.

Common curlymesquite was collected from two 32-ha pastures. One pasture, designated the continuous pasture, has been under heavy continuous grazing (5.4-4.6 ha/ AU) with cattle, sheep, and goats in the ratio of 60:20:20 since 1949. The second pasture, designated the rotation pasture, was grazed lightly (16 ha/AU) with cattle and goats from 1949 to 1969 , and has been in a 4-pasture,

Authors are, respectively graduate research assistant and associate professor, Department of Range Science, Texas A\&M University, College Station, Texas 77843. Gcorge is now senior environmental scientist, El Paso Natural Gas Co., El Paso, Texas.

This report is published with approval of the Director, Texas Agricultural Experiment Station, as TA-15630.

Manuscript received July 20, 1979. 3-herd deferred-rotation grazing system ( $5.2 \mathrm{ha} / \mathrm{AU}$ ) with cattle, sheep, and goats in the ratio of 60:20:20 since 1969 .

The litterbag technique was used to study decomposition (Wiegert and Evans 1964). Dormant common curlymesquite herbage was clipped from each of the two pastures in January 1976 and oven-dried at $65^{\circ} \mathrm{C}$. Five grams were placed in $15 \times 15 \mathrm{~cm}$ fiberglass screen litterbags with mesh size of $2 \mathrm{~mm}$. On May 20, 1976, three replications of litterbags from each pasture were placed on the soil surface in a grazing exclosure and secured at each corner with steel nails. On each collection date, one litterbag from each replication per pasture was collected, for a total of 6 litterbags per collection date. Time between collection dates varied from 13 to 73 days over a 345-day period. Litterbags were placed in individual paper sacks and transported to the laboratory where soil adhering to the litter was removed. The litter was dried at $65^{\circ} \mathrm{C}$ and weighed. Litter was ground to pass a $0.5-\mathrm{mm}$ (40 mesh) sieve and stored in airtight plastic bags. Total nitrogen was determined by the microKjeldahl method (Ass. Official Anal. Chem. 1970). Carbon was determined by the modified Walkley-Black method of Bremner and Jenkinson (1960), and ash residue was measured by heating at $450^{\circ}$ for 8 hours. Precipitation, temperature, and potential evaporation data were obtained from Station records.

\section{Results and Discussion}

Herbage decomposition in litterbags, measured as percentage of initial weight remaining, exhibited a characteristic exponential curve (Fig. 1). The exponential loss of weight, typified by rapid initial weight loss followed by a decelerating rate, is commonly found in decomposition studies (Olson 1963). Because decomposition of herbage from the two pastures did not differ $(P<0.05)$ between pastures for any collection date, the data were combined.

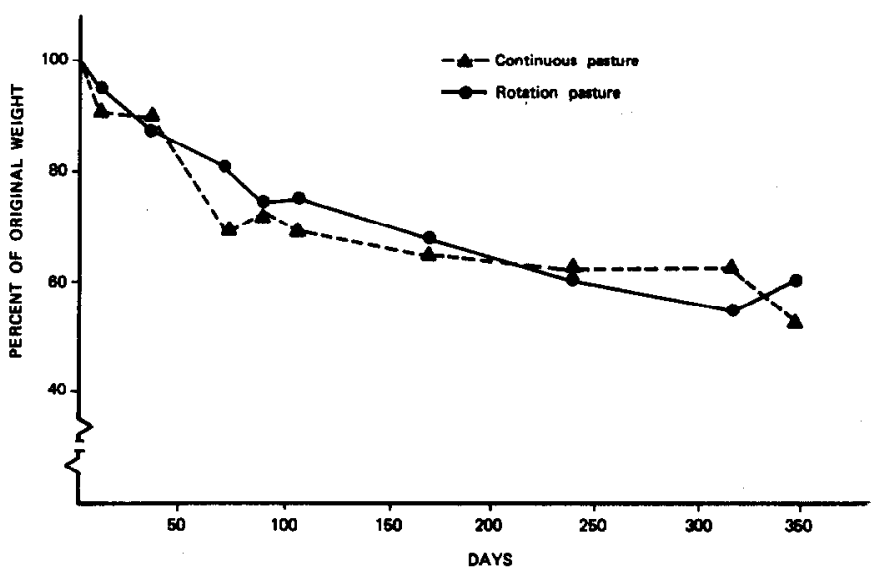

Fig. 1. Decomposition of herbage in litterbags from continuous and rotation pastures on the Sonora Research Station. 
Table 1. Average decomposition of common curlymesquite herbage in litterbags on the Sonora Research Station measured as percentage of initial weight remaining and rate of decomposition $(r)$. The values represent the pooled data of the continuous and rotation pastures $(N=6 /$ date).

\begin{tabular}{cccc}
\hline $\begin{array}{c}\text { Collection } \\
\text { date }\end{array}$ & $\begin{array}{c}\text { Time } \\
\text { (days) }\end{array}$ & $\begin{array}{c}\text { Percentage of } \\
\text { initial weight }\end{array}$ & $\begin{array}{c}r \\
(\mathrm{mg} / \mathrm{g} / \text { day) }\end{array}$ \\
\hline $5 / 20 / 76$ & 0 & 100 & - \\
$6 / 01 / 76$ & 13 & 92.6 & 5.94 \\
$6 / 29 / 76$ & 41 & 88.6 & 1.32 \\
$7 / 29 / 76$ & 71 & 75.4 & 5.70 \\
$8 / 17 / 76$ & 90 & 73.4 & 1.28 \\
$9 / 02 / 76$ & 106 & 72.2 & 1.10 \\
$11 / 04 / 77$ & 169 & 66.8 & 1.22 \\
$1 / 12 / 77$ & 238 & 61.0 & 1.32 \\
$3 / 25 / 77$ & 311 & 58.6 & 0.57 \\
$4 / 29 / 77$ & 345 & 56.2 & 1.32 \\
\hline
\end{tabular}

Therefore, all discussion of herbage decomposition will involve pooled data for both pastures.

Rate of decomposition was determined by the formula of Weigert and Evans (1964):

where:

$$
r=\frac{\log _{e}\left(W_{0} / W_{t}\right)}{t_{t}-t_{0}} \times 1000
$$

$r=$ rate of decomposition in $\mathrm{mg} / \mathrm{g} /$ day

$W_{0}=$ initial weight at time zero

$W_{\mathrm{t}}=$ weight at time $t$

$t=$ time in days.

Decomposition rate $(r)$ was $2.19 \mathrm{mg} / \mathrm{g} /$ day for the entire 345 day study period (Table 1). Rate of decomposition during the growing season (May 20-November 4) was $2.75 \mathrm{mg} / \mathrm{g}$ day, but decreased to $0.90 \mathrm{mg} / \mathrm{g} /$ day during winter. Time required for one-half of the initial weight of material to decompose (T1/2) was calculated by the solution $0.5=e^{-k t}$ for $t$, which is $-1\left(\log _{e} 0.5\right) / k=$ $0.693 / k$, where $k$ is the percentage weight loss per day (Olson 1963). $\mathrm{T} 1 / 2$ was calculated as 453 days.

Through day 238, multiple regression analysis indicated that over $96 \%$ of the variation in decomposition rate $(r)$ of common curlymesquite herbage was accounted for by abiotic factors and cumulative time. Antecedent potential evaporation since the preceding collection date, cumulative time and total precipitation since the preceding collection date increased the coefficient of determination $\left(R^{2}\right)$ by $0.51,0.30$, and 0.15 , respectively. The regression equation was:

$$
r=8.07-0.028(\mathrm{X} 1)-0.019(\mathrm{X} 2)+0.008(\mathrm{X} 3)
$$

where:

$\mathrm{r}=$ rate of decomposition in $\mathrm{mg} / \mathrm{g} /$ day

$\mathrm{X} 1=$ total measured potential evaporation $(\mathrm{mm})$ since the preceding collection date
$\mathrm{X} 2=$ cumulative time (days)

$\mathrm{X} 3=$ total precipitation $(\mathrm{mm})$ since the preceding collection date

Standard error of the estimate of the regression equation was about $27 \%$ of the mean observed values of $r(X=2.80 \mathrm{mg} / \mathrm{g} /$ day $)$. The regression equation was significant at the $P<0.10$ level. Missing climatological data prevented development of a regression equation for the entire 345 days of the study. The relationship between abiotic factors and decomposition rate has been shown by Jenny et al. (1949) and Hunt (1977). Nyhan (1976) also found time and environmental factors to most accurately predict decomposition of blue grama (Bouteloua gracilis [H.B.K.] Lag. ex. Steud.) herbage. Vossbrinck et al. (1979) concluded that abiotic factors play a minor role in decomposition of blue grama litter. They determined that microbial and mesofauna activity contributed most to decomposition amounts and rates. Thus, correlations of abiotic factors to decomposition rates is more probably related to their influence on activity of decomposer organisms rather than as a direct influence on decomposition. The 2-mm mesh bags used in this investigation would have been sufficiently large for mesofauna to be active according to these authors.

Percentage nitrogen increased in decomposing herbage with time (Table 2). This is in accord with the results of other studies (Koelling and Kucera 1965; Pendleton 1972; Sowden and Ivarson 1974). At day zero, percent nitrogen in herbage from the continuous pasture was significantly greater than that from the rotation pasture. Throughout the study, percentage nitrogen was generally greater in decomposing herbage from the continuous pasture, although differences between pastures were not significant after day zero and became less pronounced with time. Percentage nitrogen was negatively correlated with percent of initial herbage weight remaining in litterbags. Correlation coefficients were -0.83 and -0.91 for herbage from the continuous and rotation pastures, respectively.

Sowden and Ivarson (1974) found that increased nitrogen percentage of decomposing forest litter was related to weight loss of the litter. Although percentage nitrogen in decomposing herbage increased with time, the amount of nitrogen held in decomposing herbage decreased from 38.8 to $26.1 \mathrm{mg} \mathrm{N}$ per $5 \mathrm{~g}$ herbage and from 29.2 to $22.4 \mathrm{mg} \mathrm{N}$ per $5 \mathrm{~g}$ herbage for the continuous and rotation pastures, respectively. This difference in nitrogen content represents return to the soil nitrogen pool or assimilation by soil organisms.

Percentage carbon of the decomposing herbage decreased significantly from May to July and from November to the following April for both pastures (Table 2). This decrease in percentage carbon over time agrees with results of De LaCruz and Gabriel (1974) for decomposing Juncus roemerianus Scheele leaves and Nyhan (1975) for decomposing Bouteloua gracilis herbage. Correlation coefficients between percent carbon and percent of initial herbage remaining were 0.99 and 0.99 for herbage from the contin-

Table 2. Chemical characteristics of decomposing herbage in litterbags from continuous and rotation pastures on the Sonora Research Station.

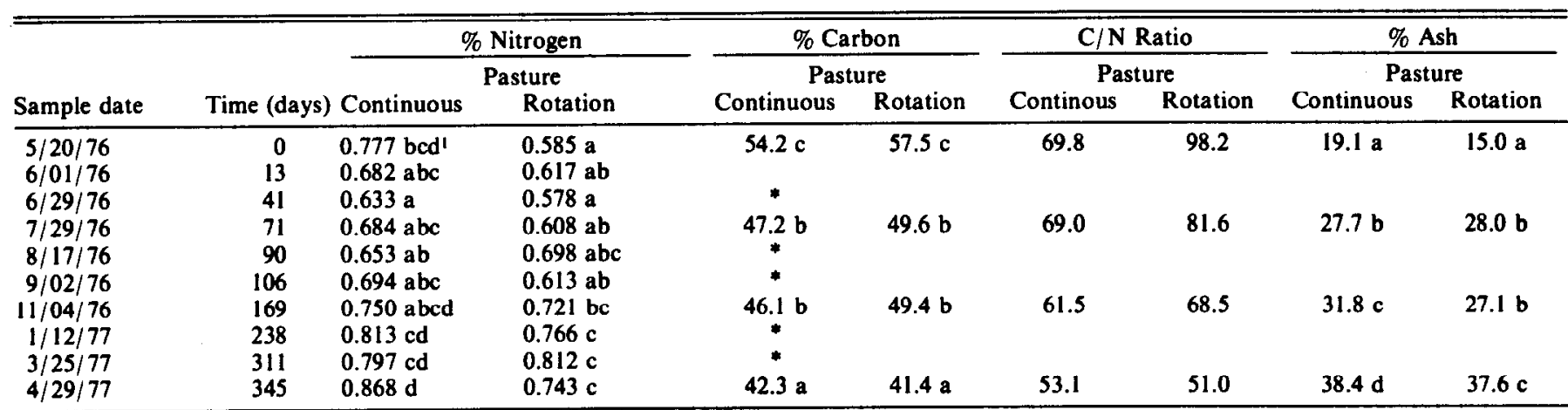

IValues followed by different letters in the same column are different at the 0.05 level.

- Carbon, $\mathrm{C} / \mathrm{N}$ ratio and ash not determined for these dates. 
uous and rotation pastures, respectively.

Carbon/nitrogen $(C / N)$ ratio of decomposing herbage in litterbags decreased throughout the study (Table 2). Because the $\mathrm{C} / \mathrm{N}$ ratios were determined from means, they were not statistically analyzed. However, some trends are evident. In the early stages of the study, the $\mathrm{C} / \mathrm{N}$ ratio of herbage from the rotation pasture was much higher than that from the continuous pasture. However, by day $345, \mathrm{C} / \mathrm{N}$ ratios were nearly equal between pastures. The importance of carbon/nitrogen ratios in controlling decomposition rates was stressed by Hutchings and Martin (1934) and Witkamp (1966).

Percent ash in decomposing common curlymesquite herbage increased from 19.1 to $38.4 \%$ for herbage from the continuous pasture and from 15.0 to $37.6 \%$ for herbage from the rotation pasture (Table 2). Both increases were significant at the 0.05 level. Percentage ash in decomposing herbage was highly negatively correlated with percent of initial herbage weight remaining in litterbags. Correlation coefficients were -0.99 and -0.99 for herbage from the continuous and rotation pastures, respectively. Percentage ash in decomposing common curlymesquite herbage obtained in this study agree with Koelling and Kucera (1965) for percent ash in decomposing bluestem herbage.

This work documented information on dynamics of decomposing common curlymesquite herbage on the Edwards Plateau of Texas and will contribute to a knowledge of nutrient cycling in this grassland. Rate of decomposition of common curlymesquite herbage was shown not to differ between the two grazing treatments. Chemical constituents of decomposing herbage did differ early in the decomposition process, but became more similar with time.

\section{Literature Cited}

Association of Official Analytical Chemists. 1970. Official methods of analysis. W. Horowitz (ed.), Washington, D.C. 1015 p.

Bremner, J.M., and D.S. Jenkinson. 1960. Determination of organic carbon in soils. I. Oxidation by dichromate of organic matter in soil and plant materials. J. Soil Sci. 11:394-402.
DeLaCruz, A.A., and B.C. Gabriel. 1974. Caloric, elemental, and nutritive changes in decomposing Juncus roemerianus leaves. Ecology 55:882886.

Gould, F.W. 1975. The Grasses of Texas. Texas A\&M Univ. Press, College Station, Texas. $653 \mathrm{p}$.

Hunt, H.W. 1977. A simulation model for decomposition in grasslands. Ecology 58:469-484.

Hutchings, I.J., and T.L. Martin. 1934. Influence of the carbon-nitrogen ratios of organic matter on rate of decomposition in the soil. J. Amer. Soc. Agron. 26:333-341.

Jenny, H.S.P. Gessel, and F.T. Bingham. 1949. Comparative study of decomposition rate of organic matter in temperate and tropical regions. Soil Sci. 68:419-432.

Koelling, M.R., and C.L. Kucera. 1965. Dry matter losses and mineral leaching in bluestem standing crop and litter. Ecology 46:529-532.

Nyhan, J.W. 1975. Decomposition of carbon-14 labeled plant materials in a grassland soil under field conditions. Soil Sci. Soc. Amer. Proc. 39:643648.

Nyhan. J.W. 1976. Influence of soil temperature and water tension on the decomposition rate of carbon-14 labeled herbage. Soil Sci. 121:288-293.

Olson, J.S. 1963. Energy storage and the balance of producers and decomposers in ecological systems. Ecology 44:322-331.

Pendleton, D.F. 1972. Degradation of grassland plants. MS Thesis. Colorado State Univ. 37 p.

Soil Conserv. Serv. 1968. Soil survey of Sutton County, Texas. U.S. Dep. Agr., U.S. Govt. Printing Office, Washington, D.C. 33 p.

Sowden, F.J., and K.C. Ivarson. 1974. Effects of temperature on changes in the nitrogenous constituents of mixed forest litters during composition after inoculation with various microbial cultures. Can J. Soil. 54:387. 394.

Vossbrinck, C.R., D.C. Coleman, and T.A. Woolley. 1979. Abiotic and biotic factors in litter decomposition in a semiarid grassland. Ecology 60:265-271.

Weigert, R.G., and F.C. Evans. 1964. Primary production and the disappearance of dead vegetation on an old field in southeastern Michigan. Ecology 45:49-63.

Witkamp, M. 1966. Decomposition of leaf litter in relation to environment, microflora, and microbial respiration. Ecology 47:194-201.

\section{Membership in the Society for Range Management. . .}

is open to those engaged in or interested in the study. management, or use of range ecosystems and the intelligent use of all range resources

includes research scientists, ranchers, governmental agency administrators and technical personnel. teachers, students, and people from the business community

provides members with two publications-one oriented to research (Journal of Range Management) and the other oriented to practical resource management (Rangelands) offers opportunities for face-to-face exchange of ideas at local, national, and intemational meetings of the Society.

Dues vary according to type of membership and geographical section. For application forms and additional information, contact the: Executive Secretary Soclety for Range Manggement

2760 West Fifth Avenue

Denver, Colorado 80204 (303) 571-0174 